\title{
Favela-Bairro, 25 anos: \\ conversa com o arquiteto e urbanista Sérgio Magalhães (SM) ${ }^{1}$
}

\author{
Entrevistadores \\ James Miyamoto (J), Stephen Buckman (S)
}

\begin{abstract}
1 Sérgio Magalhães é Presidente do 27o Congresso Mundial de Arquitetos UIA2020, a ser realizado em 2020, no Rio de Janeiro, RJ, Brasil. É professor do Programa de Pós-Graduação em Urbanismo (PROURB-FAU-UFRJ), onde realizou Doutorado (2005). É arquiteto formado pela Faculdade de Arquitetura-UFRGS (1967). Foi Presidente do IAB-Nacional, Subsecretário de Urbanismo da Prefeitura da Cidade do Rio de Janeiro (1986-1988), Diretor de Urbanismo da Prefeitura de Niterói (1989-1992), Secretário Municipal de Habitação da Prefeitura da Cidade do Rio de Janeiro (19932000), Secretário de Estado de Projetos Especiais do Governo do Estado do Rio de Janeiro (20012002) e Subsecretário de Estado do Desenvolvimento Urbano (2003-2004).
\end{abstract}

Durante suas gestões na Secretaria Municipal de Habitação da Prefeitura da Cidade do Rio de Janeiro, nos Governos dos Prefeitos César Maia (1993-1996) e Luiz Paulo Conde (1997-2000), idealizou e foi responsável direto pelo programa Favela-Bairro que beneficiou 155 favelas, através de obras de urbanização e paisagismo, implantação de infraestrutura básica, construção de habitações, ações sociais etc.

... continua na próxima página ...
J,S: Sérgio, você pode dar um panorama do [programa] Favela-Bairro? O que deu certo? Como as comunidades viram a chegada do Favela-Bairro? Como elas vêem o Favela-Bairro, 25 anos depois? Como você vê o Favela-Bairro, hoje?

SM: Bom, fazem vinte e cinco anos, né?! Nos primeiros dez anos, foi uma experiência muito exitosa. Foi muito bem sucedida, na minha avaliação. E depois ela perdeu muito, pela falta da Prefeitura e do Governo do Estado que não promoviam manutenção... Os serviços públicos se deterioram, o Programa se debilitou.

\section{J,S: Por uma rixa política?}

SM: Não, mas porque a desigualdade é muito forte no Brasil. Não, acho que não foi rixa política. Acho que, na essência, as áreas pobres, as áreas populares, tem muita dificuldade de reconhecimento dos governos. Há um processo político que em determinado momento valoriza e logo depois rejeita. A ideia de que se gaste recursos públicos em áreas pobres, especialmente em favelas, - que tem uma simbologia especial, - é aplaudida, inicialmente, e depois há rejeição.

\section{J,S: Pelas camadas mais abastadas? Pela sociedade como um todo?}

SM: Eu não separaria muito isso... Por exemplo, o próprio César Maia foi o Prefeito que implantou o Favela Bairro. Se deve a ele a implantação do Favela Bairro. Nos governos seguintes dele, ele recuou. Então, nós tivemos um primeiro governo César Maia muito efetivo. Depois tivemos um governo Conde muito efetivo. Depois, no segundo governo Cesar Maia, já houve uma mudança. A Secretária de Habitação que me sucedeu fez críticas públicas ao Favela-Bairro que evidenciavam pelo menos incompreensão, se não rejeição. Depois, se diminuiu muito a manutenção. 
A conversa com o prof. Sérgio Magalhães busca resgatar a experiência do Programa Favela Bairro, 25 anos depois de sua implantação na cidade do Rio de Janeiro. Esta importante experiência trouxe muitas contribuições para o trabalho de qualificação urbanística em favelas, tendo influenciado diversas iniciativas no Brasil e no exterior.

* James Shoiti Miyamoto é Arquiteto e Urbanista, professor da faculdade de Arquitetura e Urbanismo da Universidade Federal do Rio de Janeiro, orcid <http://orcid. org/0000-0002-4710-4339>. Stephen Buckman é PhD em Geografia, professor da Clemson University, ORCID <http://orcid. org/ 0000-0002-8693-3519>
Eu situaria a questão em dois temas... a manutenção dos serviços públicos de infraestrutura, água, esgoto, drenagem, iluminação... que ficaram muito precários, - isso sinaliza para a população muito mal,- e o segundo, o serviço público que é essencial, o controle urbanístico, que deixou de existir... Então a ausência do controle urbanístico ajudou o desenvolvimento das forças paralelas, sobretudo das milícias. Mas não só. Sem controle urbanístico, enfraquece-se muito a presença do Estado. Com o enfraquecimento da presença do Estado, tudo se deteriora.

\section{J,S: Pois é, havia iniciativas como o POUSO...}

SM: Sim, o POUSO terminou, praticamente. O POUSO, Posto de Orientação Urbanística e Social, era um escritório da Prefeitura na favela, encarregado de orientar a população quanto as limitações urbanísticas. Não deixar construir onde não pode. Permitir que se construa dentro da legislaçãoque foi especificamente feita pelo Favela-Bairro. Naquele determinado lugar só poderia ter dois andares, não poderia ter quarto [andares]. Noutro, só podia ter três [andares] e não cinco [andares]. Quando isso deixa de existir, quando a presença da Prefeitura com o controle urbanístico e edilício deixa de existir, quem é poderoso, quem tem o poder na favela,- muitas vezes bandido, -toma conta. Então, essa uma questão central para mim, na segunda metade desses 25 anos... E isso ocorreu com as favelas que tiveram o programa Favela-Bairro, mas [também] nas áreas populares, em geral, mesmo não sendo favela. Então, hoje, eu acho que a realidade da cidade do Rio de Janeiro é de uma parcela muito importante do território sem a efetiva guarda por parte do Estado. Esse é um drama crucial porque, respondendo a primeira pergunta também, lideranças da primeira parte do Favela, que aderiram ao Favela-Bairro e que foram muito importantes para que o programa fosse bem sucedido... Essas lideranças, quando o Estado saiu, ficaram na mira dos poderosos que entraram ou que se fortaleceram.

\section{J,S: Do poder paralelo?}

SM: Sim, do poder paralelo. Então, essas primeiras lideranças foram afastadas. Muitas delas foram mortas e grande parte teve que sair das favelas. Aí, passou um certo tempo e o Estado implantou as UPP. Ao implantar as UPP, parecia que estava tudo recuperado de novo. Então surgem novas lideranças, essas lideranças se fortalecem, mas há a queda das UPPs e essas lideranças são de novo dizimadas. Então, há uma crise política de representação por dentro da crise política de representação da democracia brasileira como um todo, nessas áreas populares, que é muito importante.

O Favela-Bairro objetivavaimplantar as redes de infraestrutura e os serviços públicos que não havia nas favelas. Fazia com que a favela ficasse próxima da cidade formal. Era esse o objetivo do Favela-Bairro e ele foi cumprido ou foi parcialmente cumprido, mas depois se perdeu...

\section{J,S: Quantas comunidades foram beneficiadas?}

SM: Quando eu saí, nós estávamos trabalhando com 155 favelas e uma população de 550 mil pessoas. Vamos admitir fazer um paralelo singelo, paralelo muito simples. Nós temos uma favela, uma determinada comunidade, onde era raro ter infraestrutura. Nós a implantamos. Colocamos água, esgoto, drenagem, abrimos ruas, pavimentamos, 
criamos calçadas, iluminação pública, creche, escola, estação de tratamento de esgoto. Fizemos tudo isso. Vamos admitir que isso, mantida a diferença morfológica entre favela e Ipanema, - porque tem uma diferença morfológica essencial - vamos admitir que os serviços públicos estivessem mais ou menos equilibrados e as infraestruturas também. Então,vamos admitir que feito esses serviços e os dois razoavelmente equilibrados, o governo só fique na favela e não faça nada em Ipanema. Então, por exemplo, em Ipanema, o [sistema de] esgoto estragou e o esgoto não vai ser tratado. A lâmpada queimou e não se refaz a iluminação. Aí começa um cara construindo na calçada e o governo não faz nada. Mas o governo faz tudo isso na favela. Em quanto tempo a favela será Ipanema e Ipanema será a favela?

Essa é a questão! Porque uma vez realizada a infraestrutura e implantada a escola, a creche etc., o governo saiu e... ficou só Ipanema!

\section{J,S: E o poder paralelo se apropriaria de Ipanema também...}

SM: Sim, em quinze dias...

\section{J,S: Então, para você, o Favela-Bairro foi um sucesso, né?}

SM: Sem modéstia, eu acho que o Favela-Bairro é a melhor experiência, do Brasil, ao final do século $X X$, sob o ponto de vista urbanístico. Foi uma uma experiência absolutamente inovadora com larga repercussão para cidades brasileiras e outras cidades do mundo. Por exemplo, foi matriz da grande mudança que houve na Colômbia...

E foi um aprendizado muito importante sob o ponto de vista do desenho urbanístico, da relação de projeto com o morador, da participação da sociedade na definição das questões do habitat...Acho que o Favela-Bairro foi muito inovador . Por circunstâncias políticas e econômicas muito especiais, também foi muito bem sucedido nesse aspecto (da inovação).

Mas o que, hoje, eu avalio é que essa é uma dimensão que não resolve todas as questões. Porque a dimensão política do Estado foi fraca. Ela não se desenvolveu de modo a integrar a cidade como um todo e isso não é uma questão que se resolva no Favela Bairro.

Isso não é tampouco uma questão só do Rio de Janeiro. Isso decorre da grande desigualdade na sociedade brasileira e em muitos países do mundo. Nesse mesmo período do Favela-Bairro, nesses 25 anos do Favela-Bairro, aumentou a desigualdade de renda entre os mais ricos e os mais pobres no Brasil e aumentou muito! O estudo do francês [Thomas] Picketty demonstra isso. No mesmo período, o IBGE avaliou que aumentamos a distância entre o 1\% mais rico e o 50\% mais pobres. No Brasil, o 1\% mais rico, hoje, detém $28 \%$ da renda. A desigualdade é maior do que nos países árabes. Então, não dá para se imaginar que uma cidade possa florescer autonomamente, porque, entranhada na própria política do país, a desigualdade é uma questão central. Como se combate a desigualdade? A desigualdade não se combate só na renda. A renda é importante, mas se combatesobretudo na prestação de serviços públicos.

Então, quando você reduz a prestação de serviços públicos nas áreas pobres, você está aumentando a desigualdade. Você, privilegiando os serviços públicos nas áreas 
ricas, está aumentando as desigualdades. Então, o que ocorre no Brasil nesses últimos tempos, apesar do discurso dizer o contrário, é o aumento da desigualdade.

Quando não se tem água, não só há um problema de saúde pública,como também há um problema de economia, porque as pessoas têm que pagar a água que é mais cara do que a água encanada... Quanto não há esgoto, as pessoas tem menos saúde, portanto têm menos força econômica também. Ficam mais doentes e debilitadas. Quando não há uma boa iluminação, a mesma coisa, reduzem-se muito as possibilidades. Quando não há crédito para a família ter a casa, ela perde energia com isso. Então quando esses serviços públicos não existem ou são precários, não basta a renda ser uma resposta, porque é isso que de fato significa aumento das desigualdades. É preciso que os serviços públicossejam canalizados prioritariamente para onde há mais dificuldades, para poder diminuir essa desigualdade.

E a desigualdade não se resolve só na base do voto, na política, se resolve também por todas essas ações, onde a questão urbanística é muitíssimo importante numa situação como a brasileira. Onde não se investe em transporte de massa e você tem uma cidade com doze milhões de habitantes, onde, nos últimos dez anos, o que se investiu no transporte de massa foi para ligar a Barra da Tijuca à Zona Sul, enquanto 95\% da população está do outro lado.

Então,os serviços públicos tratados desigualmente em benefício dos mais ricos aumentam a desigualdade, independentemente da renda se mantera mesma. Coisa que também não aconteceu. A renda também aumentou as desigualdades.

O Favela-Bairro está colocado em um contexto, em que ele não pode ter a resposta para tudo. Ele tem a resposta parcial, desde que o Estado acompanhe e entenda que a solução é fazer uma sociedade mais equitativa. Mas, se o Estado imagina que a cidade mais equitativa não é uma atribuição sua, não adianta a cidade promover o turismo, promover o pólo petroquímico, criar grandes expectativas em relação aos ativos econômicos, porque a base da sociedade não tem como acompanhar...Então falta educação, não há aumentoda produtividade...

Isso tem a ver com o urbanismo. Isso tem a ver com as condições que a cidade oferece. A economia é urbana. Por que no Brasil, nos últimos vinte e poucos anos, cresceu mais a economia extrativista... soja, carne, minério de ferro, mesmo a economia estando na cidade? Porque a cidade está no abandono!

\section{J,S: Num certo momento, houve um ânimo de que estivéssemos saindo de uma certa situação de precariedade e que estivéssemos progredindo e galgando patamares mais equilibrados, como você vê a Colômbia nesses termos? Porque está dando certo...?}

SM: A Colômbia estava em uma situação muito mais difícil do que o Brasil. Uma guerra guerra civil de 50 anos, metade do território ou mais tomado pelo narcotráfico e ainda mais com viés ideológico. Alí, houve uma mobilização da sociedade que permitiu essa modificação. Tem que ver se a paz vai perdurar. Agora, o Brasil, desde 2008, parou de investor em urbanização deáreas pobres. O Governo Federal sustou praticamente o investimento em áreas populares para urbanização. Botou todo o dinheiro no "Minha 
Casa Minha Vida. Isso tem doze ou treze anos. Não é pouca coisa! Em vinte e cinco [anos]... Então, houve uma opção brasileira, efetiva, dos recursos públicos,em outra linha que não o reconhecimento da cidade existente. Onde os pobres moram? Os pobres moram nos bairros que eles construíram. Os bairros que eles construíram tem carência de infraestrutura. Tem casa, mas não tem infraestrutura. A infraestrutura quem tem que botar é o poder público. Se o poder público, ao invés de fazer infraestrutura, resolve fazer casa...

\section{J,S: Mas existe um déficit habitacional...}

SM: Não fez efeito nenhum... O Minha Casa, Minha Vida não fez efeito nenhum! O déficit era de seis milhões antes e continua seis milhões agora.

\section{J,S: Mas porque isso então?}

SM: Porque a demanda é muito maior do que foi produzido oficialmente. O Brasil constrói um milhão e meio e novas moradias por ano. Nesse período, portanto, o país construiu mais de quinze milhões de moradias. O Minha Casa Minha Vida construiu três milhões de moradias e gastou 500 bilhões de reais. Com 500 bilhões de reais, poderiam ter investido em infraestrutura nas cidades existentes e dado um outro patamar, completamente diferente.

\section{J,S: Os números são dessa ordem? 500 bilhões de reais no Minha Casa, Minha Vida?}

SM: Para você ter uma ideia,no Favela Bairro, durante oito anos... Aliás, não só no Favela-Bairro, mas também no "Morar sem Risco", na urbanização de favelas, gastamos um bilhão e meio [de reais]. Um bilhão e meio, se você colocar a inflação, você vai para dois bilhões e meio ou três bilhões [de reais]... Compare com 500 bilhões...

J,S: Estávamos conversando numa comunidade, Vila Canoas, e o ex-Presidente da Associação de Moradores, disse que houve o Bairrinho, - não exatamente o Favela-Bairro, - e que quando foi chegando época da eleição, tudo foi parando... E todas as iniciativas:a creche estava sendo construída, o posto de saúde...e parou tudo! Então, ele disse que foi a um programa de televisão, um programa jornalístico, talvez o RJTV, e deu uma entrevista dizendo que tudo tinha parado. Parece que o César Maia ficou muito incomodado com ele. Deu uma bronca nele, mas, três dias depois, os operários estavam retomando a obra...Então teve um momento que, pode não ter sido por rixa política, mas, teve um momento, como você mesmo falou,no primeiro governo Cesar Maia, ele queconcordou com suas linhas políticas...

SM: Ele era o Prefeito...

J,S: Pois é...Concordou com as linhas que você...

SM: Ele que aprovou... Ele que me nomeou...

J,S: Pois é... e quando, oito anos depois, ele volta. Volta com outra perspectiva... Por isso, no início eu perguntei se era uma questão de rixa política...Por que uma pessoa muda tanto assim...?! 
SM: É. Eu não sei se é só rixa política...O que é... Mas que mudou, mudou...

J,S: Porque no primeiro governo dele, o [Luiz Paulo] Conde era Secretário de Urbanismo e você era de Habitação, não é isso? Aí depois, o Conde vira Prefeito e você continuou na Habitação, certo? Quando vem o Governo seguinte, vocês todos saem, naturalmente. Não tinha mais sentido...

SM: É claro. Aí, no meu lugar ficou a Solange Amaral. Quando ela entra, ela diz: "agora não vou mais querer botar clarabóia em creche, nem banca de mármore em creche". Critica...

Quando eu saí, tínhamos um contrato com o BID que já tinha andado bastante. Havia recursos ali, mas ao invés de terminar no prazo de um ano que era o nosso prazo, levou doze[anos]...

\section{J,S: E você tem contato com essas comunidades?}

SM: Não.

J,S: Não? Não tem contato mais nenhum? Nem uma relação com Associações de Moradores...

SM: Não. Como eu falei, grande parte deles foi...

J,S: Dizimado, né?! Ou saiu ou foi morto, né?!

SM: Morto! Muitos. Não foram poucos não! Não foi um ou dois não...

J,S: E inicialmente, quando vocês chegaram lá, nos primeiros Favela-Bairros, ninguém sabia o que era Favela-Bairro. Qual foi a reação da população?

SM: A população da favela era muito sestrosa. Ela duvidava que fossemos fazer, porque nunca tinha visto aquilo. Sempre os políticos indo, fazendo propaganda e ficava por isso mesmo...

No Favela-Bairro, foi a primeira vez que teve um plano geral na favela. Teve um projeto urbanístico completo, com todas as infraestruturas, identificando onde havia área de risco, construindo casas onde era necessário, abrindo ruas... e para abrir ruas tinha que tirar casas, então tinha que dar uma resposta adequada... E esses planos gerais eram apresentados em assembléia, primeiro para as lideranças, e depois apresentados para todos... em assembléia dos moradores e as pessoas participavam. E as pessoas entendem perfeitamente o que é um plano! As pessoas sabiam: "essa rua vai passar por aqui, a minha casa está aqui, não pode fazer tal coisa?!" "E porque esse campo de futebol está aqui? Não pode estar neste outro lugar?!" Uma participação muito interessante! Muitas vezes,no projeto havia mudanças decorrentes da opinião [dos moradores] que era muito pertinente...

J,S: Mas então, ao mesmo tempo que estavam receosos... 
SM: ...começaram a participar e aí, quando começaram as obras, mudou tudo, realmente mudou tudo... A adesão completa. Tanto que nosso plano era fazer quinze Favelas-Bairro... e quando eu sai, oito anos depois, eram 155.

J,S: Dez vezes mais...! Inicialmente, vocês tinham ideia de fazer quinze? E a escolha foi sob que critério?

SM: A escolha foi a seguinte: eu reuni todo mundo que entendia de favela na Prefeitura ou que tinha alguma coisa realizadaem favela e as classificamos por dificuldades. Durante três dias, fizemos uma matriz. E aí, a opção pelas quinze foi: favelas de diferentes tipologias, favelas em morro, favelasplanas, favelas à beira d'água...Quatro tipologias, distribuídas pela cidade e não concentrada numa região só. Uma vez feito isso, escolhemos as mais fáceis...

\section{J,S: Pra aprender com os erros, né?!}

SM: Exatamente. Pra não dar errado e o programa ir pra baixo. Depois que escolhemos essas quinze favelas, depois entrou mais uma, e ficaram dezesseis... Essa matriz foi ampliada e botamos as [favelas] que seriam as seguintes. Fizemos a ordem delas...E aí, o prefeito apresentou para a Câmara dos Vereadores e disse: nós vamos fazer isso!

\section{J,S: E os critérios do segundo lote foram semelhantes?}

Sérgio Magalhães: A mesma coisa...

\section{J,S: E assim foram sendo escolhidos?}

SM: E assim foram. Então os Vereadores e os moradores que poderiam ser contra, vendo que a coisa ia pra frente, aderiram.

\section{J,S: Então vocês foram escolhendo em lotes de quinze?}

SM: Depois, aumentou. Logo. Fizemos um concurso para escolher os arquitetos. Depois, fizemos outro concurso e outro concurso... Em dois, três anos já eram 50 [favelas]. E nós que éramos 80 funcionários técnicos, em toda Prefeitura, na Secretaria de Habitação, passamos a trabalhar com 1.500. Não funcionários, mas, nos escritórios... Então passou a haver um corpo técnico muito grande, com conhecimento de como fazer.

\section{J,S: Com o [programa] Rio-Cidade aconteceu mais ou menos a mesma coisa, né?!}

SM: Sim, foi. Só que no Rio-Cidade foram menos [projetos], né?!

\section{J,S: Foram uns 30, né?! Uns 15 na primeira fase...}

SM: É, mais ou menos, uns $17 \ldots$

J,S: Podemos dizer que a força do Favela-Bairro foi baseada mais no aspecto social ou na implantação de infraestrutura? 
Figura 1: Sérgio Magalhães. Fonte: autores, com autorização do entrevistado.
SM: Em ambos. Depende da favela, se o bairro do entorno tem equipamentos sociais, ela tem menos [equipamentos sociais]. Se não tem, ela tem mais... E os equipamentos sociais, como escola, creche, posto de saúde etc., nós procurávamos colocar na beira da favela para não ficar muito interiorizado. Para haver trocas sociais.

J,S: Pra encerrar, hoje, quais seriam seus sonhos como gestor público. O que você desejaria fazer, se fosse chamado a ocupar um cargo na Prefeitura, por exemplo?

SM: Meu objetivo, hoje, é a UIA2020. Espero que ela dê muito certo, pois, do contrário, terá sido um grande desperdício de uma grande oportunidade...

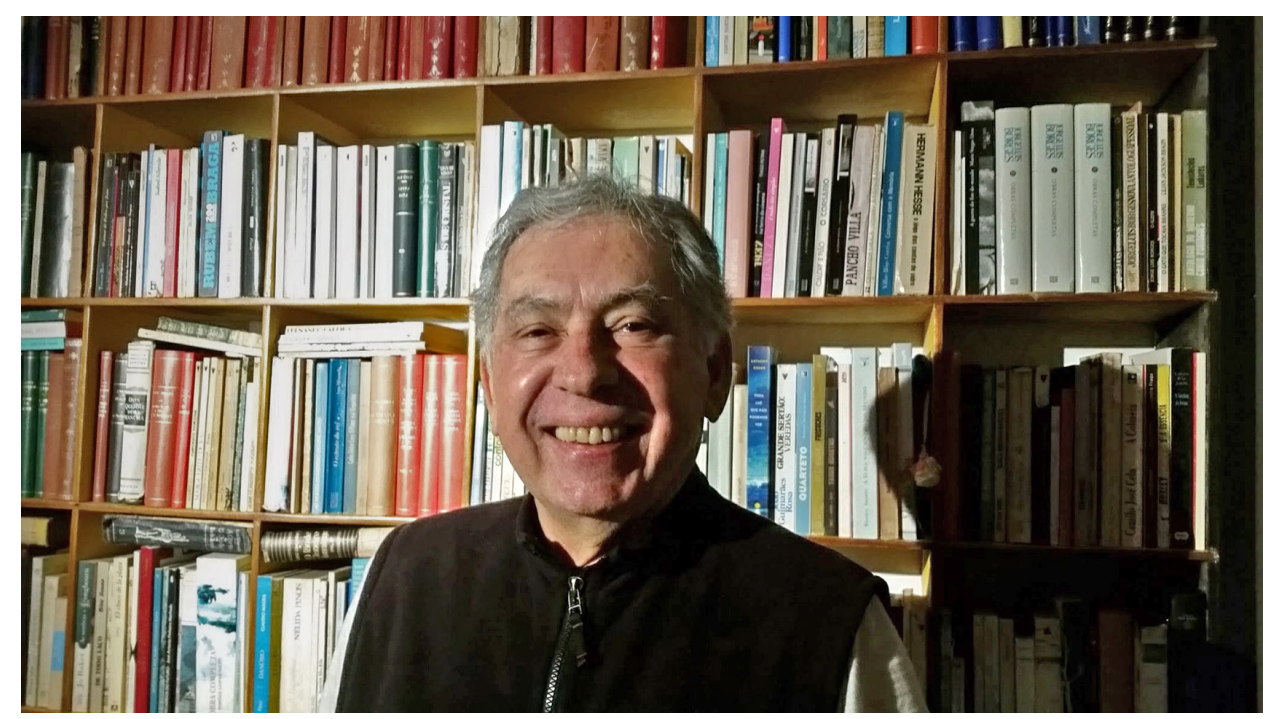

